\title{
CLARA BRANDI We the Stakeholders: The Power of Representation beyond Borders?
}

\author{
Terry Macdonald, Global Stakeholder Democracy. Power and \\ Representation Beyond Liberal States, Oxford, \\ Oxford University Press, 2008.
}

Terry Macdonald's book Global Stakeholder Democracy addresses the current discrepancy between the standard accounts of democracy, focused primarily on territorially based electoral mechanisms, and an increasingly complex, pluralist political terrain, which challenges the existing conceptual and normative resources of democratic theory. ${ }^{1}$ The main question she addresses in her book is how democracy can be retrieved, expanded and deepened in face of the existing plurality of non-state actors exercising public power in contemporary global politics. Macdonald responds to this challenge by elaborating a novel theoretical and institutional agenda for democratic reform in the global realm. By outlining her stakeholder model of global democracy, she aims at undermining the position of those who are sceptical about the legitimacy of non-state actors such as nongovernmental organisations (NGOs) in the global arena and perceive them as a threat to democracy on the grounds that they are neither elected nor accountable. She centres attention on NGOs but presents her framework as potentially applicable to a wider range of powerful global actors such as international organisations (IOs) and transnational corporations (TNCs), providing the basis for a broader approach to global democracy.

The first part of the book addresses the questions: What is it that needs to be democratically controlled in global politics? And who ought to control it? Macdonald argues that we should give up the assumption that democracy is limited to closed societies with an organisationally unified framework of power as the subject of democratic control and a community of citizens as agent of democratic control. Instead, she develops the novel concepts of 'public power' and 'stakeholder community' as the legitimate subject and agent of democratic control respectively. Macdonald identifies power as 'public' and subject to democratic control whenever it constraints the autonomy of a group of individuals in problematic ways. On the basis of this definition, she argues that actors other than states, among them NGOS, exercise public power understood in this sense in the current global order and are therefore to be regarded as subjects of democratic control. All individuals whose autonomy is problematically constrained by the exercise of public power by an NGO (or another actor) are the members of its stakeholder community and hence the agents of democratic control. Accordingly,

1. Terry Macdonald, Global Stakeholder Democracy. Power and Representation Beyond Liberal States (Oxford: Oxford University Press, 2008). 
Macdonald pictures global politics as being characterized by multiple agents of public power (for example various NGOs), envisaging them to be held accountable by their multiple overlapping stakeholder communities.

The second part of the book then addresses the challenge of building legitimate institutions for global representative decision-making: How could 'stakeholder communities' democratically control the 'public power' of NGOs and other powerful actors in global politics? Macdonald argues against the view that legitimate social choice in global politics can only be achieved through representation by nation-states and favours instead the establishment of a decision-making process on the basis of deliberation among stakeholder representatives. She contends that an account of legitimate representative agency within a representative global democracy does not necessarily require electoral mechanisms. Such representative agency can instead be based on alternative non-electoral processes of 'authorization' and 'accountability' because they provide stakeholders with some degree of political control over their representatives' actions, which corresponds to what formal elections are meant to do in electoral contexts. For Macdonald, authorization consists of two elements: first, the process of 'delegation' spells out the array of political tasks that representatives are entitled to carry out and, second, mechanisms of 'empowerment' provide representatives with the capacities to execute these tasks effectively. Accountability in turn comprises, first, mechanisms of 'transparency', which permit stakeholders to identify what representative agents are doing with their public power and, second, mechanisms of 'disempowerment' in order to weaken the agent's capacity to continue wielding public power if the stakeholders deem it appropriate. In the last chapter of her book, Macdonald illustrates the practical implications of these proposals for projects of global institutional reform and assesses how both authorization and accountability might potentially be accomplished on the basis of non-electoral mechanism so that NGOs can operate as legitimate representatives of their stakeholder constituencies.

Global Stakeholder Democracy is lucidly written and an outstanding contribution to contemporary international normative political theory for a number of reasons. First, while there has been growing interest in the idea of stakeholder democracy, undertakings to systematically address it have so far been rather limited and mostly confined to business ethics in relation to corporate stakeholder democracy; there are hardly any extensive treatments of this notion in political theory. The concept of stakeholder democracy had yet to be integrated into a theoretical and institutional framework for global institutional reform in a rigorous way, which is the task Macdonald sets out for in her book. Second, Macdonald insightfully contributes to current debates on political representation, which have become increasingly important within democratic theory. One of the main challenges for democratic theory is to examine the nature of representative claims that are not subject to elections and to explore which of them could be deemed as contributing to democracy, and in what ways. Accordingly, Macdonald's focus on non-electoral forms of representation is at the cutting edge of contemporary democratic questions. Third, as she herself also points out, those 


\section{WE THE STAKEHOLDERS: THE POWER OF REPRESENTATION BEYOND BORDERS?}

who have examined power and representation beyond borders have often exported domestic institutional schemes to the international sphere, thereby neglecting the institutional pluralism of actors at the global level. Macdonald, on the other hand, leaves traditional state-based models of democracy behind and goes beyond the current stalemate between communitarian statism and cosmopolitan universalism in order to respond to the normative consequences of the challenge of democratization in light of the existing organizational pluralism.

Last but not least, Macdonald's treatment of transnational democratic issues is a powerful plea for focusing attention not only on questions of distributive justice and ideal-theoretical, abstract rights and duties in the global sphere, which arguably are the focal point of contemporary debates about global political legitimacy and international political theory more generally, but also on nonideal questions of power, representation and participation. One of the main questions Macdonald's book seeks to explore is how the exercise of public power and its autonomy-constraining impact can be justified. One potential option is to demand a hypothetical justification to establish the justice of institutions through which political power is wielded; another possibility, which is the one Macdonald focuses her attention on, is to require actual participation in these institutions. ${ }^{2}$ Macdonald maintains that if our autonomy is constrained by public power, then this power does not only in principle need to be justifiable but rather has to be justified in actual fact by the very individuals over whom it is wielded. Macdonald's book is therefore to be welcomed as an important addition to international normative theory for the following two reasons. First, while the debate is currently dominated by discussions about transnational justice understood in a fairly narrow distributive sense, the book suggests focusing more attention on justice beyond borders in a broader sense in terms of power relations and democratic equality. Second, while the current emphasis in international political theory is on questions of hypothetical justice of institutions, Macdonald focuses on the actual process of justification through participation.

While Global Stakeholder Democracy contributes decisively to ongoing debates about democracy beyond borders, it also poses a number of questions both in terms of its theoretical dimension and in terms of its practicability. For example, several queries can be raised regarding the book's specific focus on NGO power constraining the autonomous capacities of groups of individuals. First, one can ask whether Macdonald's main spotlight on NGOs - but also her references to TNCs, IOs and states - encompasses the adequate range of powerful global public actors that have potentially problematic autonomy-constraining consequences, for example in light of the increasing importance of the complex global web of governmental networks. ${ }^{3}$ If and how the power of such networks is to be democratically controlled and to what extent Macdonald's model of non-electoral representation can be usefully applied to this intricate web, raises

2. For a discussion of this distinction in the context of the potential justification of coercive state power, see Arash Abizadeh, "Democratic Theory and Border Coercion: No Right to Unilaterally Control Your Own Borders," Political Theory 36, no. 1 (2008), 37-65.

3. Anne-Marie Slaughter, A New World Order (Princeton: Princeton University Press, 2004). 
questions that are beyond the scope of her book but point to interesting areas for future research.

Second, while it is in fact highly relevant to examine whether and how the autonomy of groups of individuals is constrained in the global arena (for instance by NGOs or by states), it seems also pertinent to question whether and how the autonomy of states is subject to constraints that are in need of (better) democratic legitimization. Consider, for example, the extent to which global institutions like the IMF can constrain the autonomous capacity of certain states, above all developing countries, to have effective control over domestic affairs. Moreover, one can query whether autonomy is only constrained by the existence of institutional actors like NGOs or IOs or whether it is also problematically limited by the very absence of certain institutional frameworks. Interestingly, Macdonald's account of what makes public power in need of democratic legitimization is focused exclusively on the impact of power and not on its organizational structure. Thereby, she avoids the conclusion that certain institutional structures must already exist as prior requirement for a project of legitimization of power through democratization. She presents the development of certain kinds of institutional characteristics such as stable and transparent structures as goal rather than as precondition for a project of democratization. In so doing, she does not only avoid that many rather intransparent political tyrannies are "off the democratic hook," 4 as she puts it, since they would not be eligible as potential contenders of democratization if she had specified completely transparent institutions as necessary preconditions for democratizing projects. Rather, she also leaves room for the very absence of institutional arrangements being problematic. The absence of institutions is problematic, for instance, in light of the existence of spillovers, that is to say, social benefits and social costs that actors do not consider in their decision-making. These spillovers in turn cause problems because they give rise to the pressurizing 'power' of certain incentives structures that have a potentially autonomy-constraining impact. Consider, for example, the infamous negative spillovers of tax competition and the corresponding pressurizing 'power' of prisoners' dilemma incentives which are said to give rise to continuously increasing constraints on states' autonomous capacities to implement tax regimes that are in accordance with their national policy objectives - unless they set up supranational institutions in order to cooperate in addressing these spillovers. More generally, the existence of such transnational spillovers could be regarded as posing problems of potentially autonomy-constraining incentive structures which can only be resolved if the span of a good's benefits and costs is matched with the span of the jurisdiction in which decisions are taken about that good. Such a notion of the autonomy-constraining 'power' of incentives poses potentially promising normative and empirical research questions about the character and the delineation of public power in the global arena beyond institutional arrangements such as NGOs, TNCs and IOs.

4. Macdonald, Global Stakeholder Democracy. Power and Representation Beyond Liberal States. p. 60 


\section{WE THE STAKEHOLDERS: THE POWER OF REPRESENTATION BEYOND BORDERS?}

Macdonald claims that her approach to non-electoral democratic representation can serve as a theoretical basis for some optimism concerning the potential democratization of NGOs and global public power more generally since it is more easily practicable than traditional electoral institutions. Yet, Macdonald herself acknowledges that the practicability of global stakeholder democracy is seriously limited for at least two main reasons. First, her proposed reliance on deliberative processes as the only mechanism for reaching collective decisions is extremely problematic in light of often contradictory and incompatible stakeholder interests, which might generate complete deadlock. Second, the multi-stakeholder-model of global representation necessitates a sufficient degree of material equality among stakeholders to guarantee equal opportunities for advancing their interests within global deliberations. In the case of electoral representation, even if there are difficulties with equal inputs during the agenda-setting phase, arguably at least an abstract equality is achieved through the universal franchise. There is no equivalent equality of influence or voice in the case of non-electoral representation, where the advantages of education, power, income and other unequally distributed resources are more likely to translate into patterns of over- and under-representation. For example, in order to authorize NGOs in democratically legitimate ways, Macdonald envisages "stakeholder signalling mechanisms, through which stakeholders can specify the tasks for which they are delegating entitlements to exercise public power, and the conditions that they are imposing upon the exercise of this power." In light of high levels of both extensive resource inequalities and power asymmetries, participation in such signalling procedures would be feasible only for some. More generally, under current conditions of inequality, ensuring the required level of equal access to stakeholder representation in the global arena is likely to be impossible. Macdonald's book can thus be seen as additionally highlighting another dimension of why and how global inequalities matters instrumentally, namely in terms of how they undermine the implementation of legitimate democratic processes beyond borders.

Yet, the main implication of these practicability challenges, above all the risk of stalemate and indecision, is that Global Stakeholder Democracy cannot provide a stand-alone framework for public global decision-making but that it must be combined with aggregative procedures. As Macdonald concedes, the most feasible way of doing this would be based on territorial state constituencies: issues which induce irresolvable conflicts of interests among stakeholder representatives and render deliberative consensus impossible should be transferred to a subsequent stage of decision-making, in which state representatives could solve such deliberative deadlocks through mechanisms of aggregative decision-making. Hence, she proposes to combine multi-stakeholder representation with a system of state-based representation, thereby generating what she characterizes as a hybrid model of representation. Accordingly, a significant part of the global stakeholder democracy model that Macdonald presents collapses into indirect democracy via representation at the state level. Still, this drawback does not alter the fact that

5. Ibid., p. 196. 
her account, by generating important questions about how to establish hybrid institutions of representation, points to future research avenues that should be given more consideration than they have received so far.

A further practicability question is whether the proposed model of stakeholder representation is excessively complex and burdensomein terms of the participatory resources it requires for the multiple, partly overlapping, jurisdictional levels. Macdonald acknowledges that the envisaged division of participatory resources has unwelcome consequences such as a potential reduction of national political allegiances but she views this as an unavoidable disadvantage of the contemporary complex political terrain. Yet, apart from additional questions that could be raised about her diagnosis of the problematic participatory consequences and their apparent inescapability, there are additional practical challenges, for instance in terms of extensive informational requirements. Even in the domestic context, some argue that citizens are not sufficiently informed about politics and that they are often apathetic, which in turn provides room for special interests to control the behaviour of those in power - difficulties that are likely to be even more relevant in the case of a complicated multi-stakeholder system beyond borders. A related challenge regarding the potential role of private interests is that NGOs rely on funding from individual donors, foundations, corporations and governments and critics charge that funding sources can seriously affect NGO policy, further contributing to making these organizations potentially dependent on special interests.

This reliance on funding in turn points to additional challenges in the context of NGO empowerment (for the sake of authorization) and disempowerment (for the sake of accountability). First, there is a potential lack of incentives for the NGO-empowering actors (donors, states, etc.) to confer the means of public empowerment in accordance with stakeholder mandates, rather than in accordance with their own private interests. Macdonald's comparison with similar potential problems of motivation in the context of the state does not seem as convincing as she suggests since the divergence between the crucial NGOempowering-actors (for example, certain donors in industrialized countries on the basis of corporate social responsibly) and NGO stakeholders (for example, indigenous peoples in a least developed country) is likely to be greater both in terms of geographical distance and in terms of potential common interests than between the empowering and the empowered actors in the context of the state.

Moreover, the current financial crisis and its problematic effects on both the supply of and demand for NGOs - and above all its consequences in terms of reduced financial support for NGOs - gives rise to further questions about the links between NGO reliance on funding and NGO (dis)empowerment in accordance with stakeholder mandates. It shows that NGOs may not be merely vulnerable to deliberately withheld funds for purposes of disempowerment, as Macdonald elaborates, but that they are also subject to general trends that are beyond their control and that have little to do with the interests of their stakeholders. Some NGOs have already had to shut down because of the recent global downturn; others are threatened by a harsh few years with diminishing funds. Such cases 


\section{WE THE STAKEHOLDERS: THE POWER OF REPRESENTATION BEYOND BORDERS?}

challenge the stakeholder democracy model to the extent that lack of funding does not necessarily correlate with deliberate public disempowerment in accordance with stakeholder mandates.

A further difficulty is the lack of coordination among NGOs, which Macdonald addresses in the context of the challenges it poses with respect to the empowerment of NGOs - above all on the basis of funding. Because of the various organizationally disconnected actors empowering NGOs, "[e]ach donor agency, for example, would need to identify the relevant stakeholders of each NGO it sought to fund, and seek a mandate from these constituents about the conditions that should be attached to the NGO's funding." "This type of process could be excessively onerous and costly, as Macdonald acknowledges. But the question is whether her idea to establish functionally or geographically oriented sector-wide mechanisms for identifying and consulting stakeholders is workable to the point that it provides a feasible basis for democratic NGO authorization. Moreover, the difficulty of coordination also deserves attention in a more general sense in light of the numerous interrelations between the multiple, often overlapping issue areas NGOs focus attention on. Above all, coordination is particularly relevant in face of challenges like environmental issues that numerous NGOs are concerned with, which involve negative externalities and prisoners' dilemma incentives that require a centrally coordinated approach in order to be tackled effectively.

Yet, against the background of these challenges in terms of practicability, it has to be stressed that Macdonald's book, as a work of political theory, seeks to outline a theoretical basis to envision a global stakeholder democracy but does not aim at presenting the corresponding fully developed blueprint for future global democratic reforms. Of course, many questions remain which would need to be tackled through further empirical research and practical experimentation. But this does not undermine the value of the book. To the contrary, Global Stakeholder Democracy is an excellent example of the kind of practical work that normative political theorists are best suited to perform: namely, conceptually framing the debate and setting the agenda for subsequent empirical investigation both in intellectual and practical terms. By aiming at the integration of normative and empirical perspectives the book exemplifies a promising approach for advancements in the field of global democracy both in theory and in practice.

6. Ibid. p. 210.

Clara Brandi

European University Institute

the globaljusticenetwork 